\title{
Desiccation sensitivity and cryopreservation of the embryonic axes of the seeds of two Acer species
}

\author{
Paweł M. Pukacki • Katarzyna Juszczyk
}

Received: 22 January 2014/Revised: 11 September 2014/Accepted: 28 October 2014/Published online: 27 November 2014 (C) The Author(s) 2014. This article is published with open access at Springerlink.com

\begin{abstract}
Key message The most dangerous stage of cryopreservation of embryonic axes of maple seeds is tissue dehydration, as excessive desiccation leads to membrane lipid peroxidation and irreversible loss of semipermeability.

Abstract We attempted cryopreservation of the embryonic axes (EAs) from orthodox seeds of Acer platanoides (Norway maple) and recalcitrant seeds of A. pseudoplatanus (sycamore), two closely related native tree species. Two pretreatment steps were tested before cryostorage: air drying and cooling to $-40{ }^{\circ} \mathrm{C}$. The aim of our study was to determine the possible types of damages to the isolated embryonic axes and their viability after exposure to liquid nitrogen $\left(\mathrm{LN}_{2},-196{ }^{\circ} \mathrm{C}\right)$. Ice nucleation in tissues was assessed by differential thermal analysis (DTA). In embryonic axes of $A$. platanoides, ice crystallization did not occur when the water content (WC) was below $26.8 \%$, while in A. pseudoplatanus, the safe level of WC that prevented ice nucleation was below $35.0 \%$. During desiccation alone, the plasma membrane integrity and viability of A. platanoides EAs were only slightly affected, while in A. pseudoplatanus, an increase in membrane breakdown and a marked decrease in the viability of EAs were observed. However, when WC exceeded $30 \%$, we observed significant damage to the tissues of both Acer species after the EAs were cooled to $-40{ }^{\circ} \mathrm{C}$ or after cryostorage in $\mathrm{LN}_{2}$. EAs of orthodox $A$. platanoides
\end{abstract}

Communicated by K. Masaka.

P. M. Pukacki $(\bowtie) \cdot$ K. Juszczyk

Institute of Dendrology, Physiology Abiotic Stress Lab, Polish

Academy of Sciences, Parkowa 5, 62-035 Kórnik, Poland

e-mail: ppukacki@man.poznan.pl tolerated dehydration to $10 \% \mathrm{WC}$, while recalcitrant $A$. pseudoplatanus to $25 \% \mathrm{WC}$ only. A very highly significant correlation was found for those species between the ice nucleation and WC, as determined from DTA analysis. Exposure of EAs to $\mathrm{LN}_{2}$ was successful (i.e., $\geq 50 \%$ axes formed seedlings) for $A$. platanoides tissues desiccated to 10-15\% WC and for A. pseudoplatanus tissues desiccated to $15-20 \% \mathrm{WC}$.

Keywords Acer - Cryopreservation · Membranes injury · Embryonic axes $\cdot$ Seeds

\section{Introduction}

Cryopreservation is considered as the best method for longterm storage of plant material (Reed 2008). Thus, plant material could be theoretically stored $(>5 \mathrm{yr})$ in $\mathrm{LN}_{2}$ without changes and loss of properties. An additional advantage of this method is relatively small storage area and low costs of maintaining samples. This applies to big gene banks: NCGRP in Fort Collins (USA), NIAR in Yamagata (Japan) or Nangis in Montpellier (France), (Engelmann 2004; Walters et al. 2004). For the majority of species and types of tissues cryopreservation protocols require an individual adaptation to the natural resistance of plants to dehydration or freezing. Thanks of this one can avoid the intracellular ice crystallization during preliminary stages of the freezing process.

Cryopreservation is the most highly recommended method for storage of recalcitrant seeds (Panis and Lambardi 2005; Benson 2008b; Engelmann 2011; Kaczmarczyk et al. 2012).

Recalcitrant seeds are more common in species growing in a tropical climate, but also in the temperate zone. 
However, among the species included in the Compendium only $7 \%$ were characterized by recalcitrant seeds (Dickie and Pritchard 2002). These seeds, which are sensitive to water loss and have distinct boundaries of resistance to water loss and low temperature, are characterized by postharvest life spans of several months to 2 years, as long as such seeds tolerate low (but not sub-zero) temperatures (Berjak and Pammenter 2008). Currently, the cryopreservation of seed embryonic axes is suggested as the most appropriate method for long-term conservation of the genetic diversity of plant species. This is because embryonic axes tolerate much more severe dehydration, which would be lethal to the entire seed (Berjak et al. 2000; Santos and Stushnoff 2002). However, the embryonic axes of seeds can be damaged during each of the following cryopreservation steps: (1) air dehydration, (2) cooling to $-40{ }^{\circ} \mathrm{C}$, (3) exposure to $\mathrm{LN}_{2}$, and (4) thawing. Successful cryopreservation is possible when during the desiccation and pre-cooling the damages of plant tissues do not occur or are minimized (Volk and Walters 2006; Fernandes et al. 2008). Determination of the critical WC, which allows survival of embryonic axes after exposure to the temperature of $\mathrm{LN}_{2}$, is the key for post-cryo viability (Pritchard and Prendergast 1986; Wesley-Smith et al. 1992). The extreme freezing stress that occurs at $-196^{\circ} \mathrm{C}$ profoundly limits chemical and physical reactions in cells. Indeed, increasing numbers of reports have demonstrated the viability of germplasms after 10-20 years of storage in $\mathrm{LN}_{2}$ (Walters et al. 2004; Panis and Lambardi 2005). Seeds of different plant species vary with respect to their sensitivity to desiccation and freezing stress, which has practical implications, as the duration of drying can influence the post-cryo viability of plant material (Niino and Sakai 1992). For recalcitrant zygotic germplasms, prolonged periods of dehydration, while not lethal themselves, may act synergistically with cooling rates and exert lethal effects (Berjak et al. 1999; Wesley-Smith et al. 2014). Some reports indicate that recalcitrant seeds with lower WC have better survival rates when they are subjected to rapid drying; however, the mechanism underlying this phenomenon is not fully known yet (Berjak et al. 2010; Pammenter and Berjak 1999). One interpretation is that the rapid dehydration inhibits the accumulation of reactive oxygen species (ROS), which cause oxidative damage in cells, and leads to an increase in the antioxidative response of low molecular weight and enzymatic antioxidants (Pukacka et al. 2011; Sershen et al. 2012). Plant tissues and cells are killed during ice nucleation inside the cells (Pukacki and McKersie 1990). This phenomenon is detected by exotherms using thermal analyses: differential thermal analysis (DTA) or differential scanning calorimetry (DSC) (Volk and Walters 2006). According to Benson et al. (2006), cryo-injury is related to two causal factors: intracellular crystallization and dehydration injury. Cellular membranes are the primary sites of freezing injury (Engelmann 2011). The cell membrane is damaged by disruption of the protein lipid structure, protein denaturation, and precipitation of solutes responsible for membrane permeability (Steponkus 1984; Kaczmarczyk et al. 2012). The peroxidation of fatty acids in phospholipids can cause extensive damage to the cell membrane if the chain reaction is not controlled, leading to large areas where the semi-permeability of the membrane is altered and thus can no longer function normally (Pukacki et al. 1991; Senaratna and McKersie 1986).

Acer species (maple and sycamore) are important trees in forest and urban areas in Poland and Europe (Suszka et al. 1996). Norway maple (Acer platanoides L.) occurs mainly in lowlands across Europe and is sometimes found in the Caucasus. The natural range of sycamore ( $A$. pseudoplatanus L.) extends from the mountains of Spain across Europe, and Poland is at the northeastern limit of its range. Within the genus Acer, seeds show varied sensitivity to desiccation and storage. Orthodox seeds of A. platanoides tolerate desiccation to water content (WC) of 6-10\% (Pukacka 1983), in contrast to recalcitrant seeds of $A$. pseudoplatanus, which show desiccation intolerance (Hong and Ellis 1990; Dickie et al. 1991; Suszka et al. 1996).

This study aimed to investigate the effects of each step of cryopreservation (dehydration, slow cooling, and exposure to $\mathrm{LN}_{2}$ ) on the survival and characteristics of the cell membranes of embryonic axes of dehydration-sensitive $A$. pseudoplatanus and dehydration-tolerant $A$. platanoides seeds. Survival was assessed by culturing the axes in vitro and by evaluating the integrity of the membranes on the basis of electrolyte leakage and lipid peroxidation. The viability of plant tissue was evaluated by recovery after culture on the woody plant medium (WPM) and triphenyltetrazolium chloride method. In this way, we attempted to determine the possible causes of damage to embryonic axes during each step of the cryopreservation process.

\section{Materials and methods}

\section{Plant material}

Seeds were collected from single trees, from a single tree of each species growing in a forest in Kórnik, Poland $\left(52^{\circ} 15^{\prime} \mathrm{N}\right.$, $17^{\circ} 04^{\prime} 20 \mathrm{E}$ ). Two species representing two seed categories of trees were utilized: orthodox Norway maple (A. platanoides L.) and recalcitrant sycamore (A. pseudoplatanus L.). After harvest, the seeds from each Acer tree, were dried at room temperature and $45 \% \mathrm{RH}$, on the sheets of paper. When the water content reaches $11 \%$ (for orthodox seeds) or $45 \%$ (for recalcitrant seeds) the seeds were stored at $-3{ }^{\circ} \mathrm{C}$ in sealed 1,000 ml polythene bags until used. 


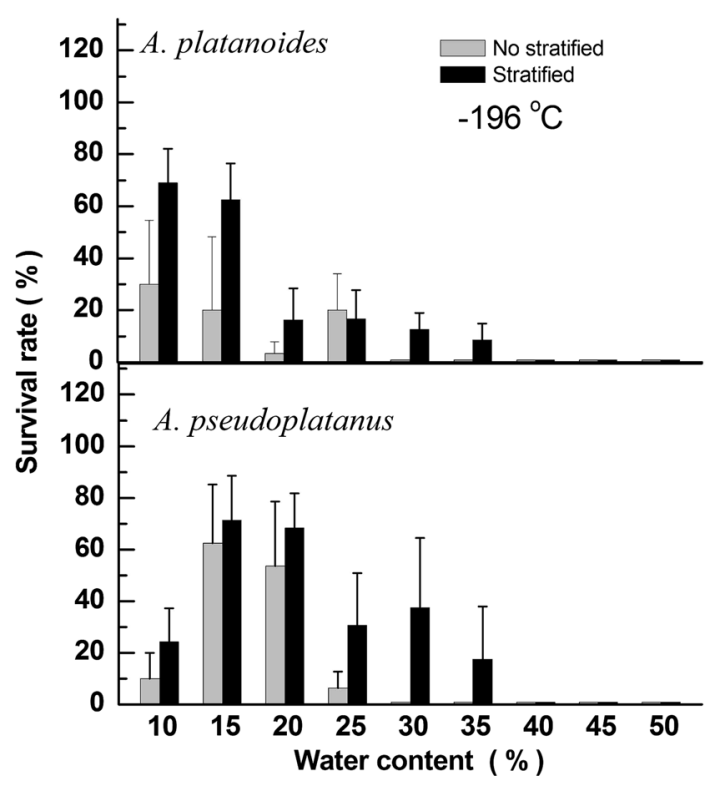

Fig. 1 The effect stratification and no stratified seeds on viability of A. platanoides and A. pseudoplatanus embryonic axes after exposure to liquid nitrogen $\left(-196{ }^{\circ} \mathrm{C}\right)$. Results are means $\pm \mathrm{SD}$

\section{Cold stratification and germination}

The set of fully imbibed seeds was stratified in $7.0 \times 11.0 \times 18.0 \mathrm{~cm}$ plastic boxes containing a $2 \mathrm{~cm}$ layer of moist rolled paper at $3{ }^{\circ} \mathrm{C}$ for $8-11$ weeks in phytotron (Suszka et al. 1996). When the first germinating seeds occurred stratification was finished. After cryopreservation, the survival of the embryonic axes of both species was 10-30\% higher compared with that of non-stratified seeds (Fig. 1). Therefore, stratified seeds were used to obtain all presented results.

\section{Desiccation and water content assays}

A total of 30 embryos per treatment were dehydrated in the rapid dehydration apparatus (Wesely-Smith et al. 2001b). Cleaned seeds were then surface sterilized, and the embryonic axes (EAs) of the seeds were isolated and desiccated on nylon gauze inserted across a PVC pipe (95 $\mathrm{mm}$ diameter, $220 \mathrm{~mm}$ in length), which acted as a support for the axes. A computer CPU cooling fan $(12 \mathrm{~V}$, $1 \mathrm{~W} ; 90 \mathrm{~mm}$ diameter) was mounted in the middle of this PE pipe, with airflow directed toward the gauze at $17 \%$ relative humidity (RH) (Wesely-Smith et al. 2001a). Activated silica gel $(500 \mathrm{~g})$ was placed in the bottom of the jar. Dehydration was applied for different periods of time (10-240 min). A digital thermo/hygrometer (dimensions: $3 \times 4 \times 0.5 \mathrm{~cm}$ ) was used for monitoring the temperature and $\mathrm{RH}$ in the apparatus during dehydration. During each stage of the dehydration process, the WC of EAs was determined gravimetrically, and the dry weight was measured after further drying at $103{ }^{\circ} \mathrm{C}$ for $24 \mathrm{~h}$. The final WC of the EAs was expressed on a fresh weight (FW) basis. Rapid dehydration in the "flash" dryer was used in all experiments described below.

Thermal analysis

DTA was used to determine the ice nucleation of supercooled tissue water. Single embryonic axes were wrapped in Al foil and placed in the DTA instrument (Pukacki and McKersie 1990). The four samples were analyzed simultaneously. This technique determines the difference in temperature between the tissues and a reference dry sample, as both are cooled or warmed at the controlled rate $15{ }^{\circ} \mathrm{C} / \mathrm{h}$. In these experiments, copper-constantan thermocouples ( $0.1 \mathrm{~mm}$ in diameter) were held on the surface of the sample, wrapped with laboratory film (Parafilm, American Can Corp., Greenwich, CT, USA). The course of the analysis was controlled and recorded with the aid of an IBM computer equipped with an analog/digital board (Type WBAAI-B8) and software developed by Omega Engineering, USA. Onset temperatures for ice nucleation were calculated from the point of the discontinuity in the baseline. Exothermic data were collected from four or eight replicates per treatment. After thermal analysis, each aluminum sample was dried at $103{ }^{\circ} \mathrm{C}$ for $24 \mathrm{~h}$ and weighed to measure the final tissue DW. The differences between FW and DW of the samples corresponded to the sample moisture content, as previously described (Pukacki and Kaminska-Rozek 2013a).

\section{Cryopreservation of embryonic axes}

After pre-dehydrating 20 EAs of each species to various water contents, each sample was separately placed into a $0.4 \times 5 \mathrm{~cm}$ aluminum tube and cryopreserved using a twostep method (Benson 2008a). First, axes in Al tubes were pre-cooled in a programmable freezer (Binder MK 53, Germany) from 0 to $-40{ }^{\circ} \mathrm{C}$ at rate of $0.25{ }^{\circ} \mathrm{C} \mathrm{min}^{-1}$, and after $40 \mathrm{~min}$, the tubes were plunged into liquid nitrogen $\left(\mathrm{LN}_{2}\right)$ at $-196{ }^{\circ} \mathrm{C}$, where they were cooled at $600{ }^{\circ} \mathrm{C} \min ^{-1}$, (the measurements were carried out in the range from $5{ }^{\circ} \mathrm{C}$ to $-140{ }^{\circ} \mathrm{C}$ ). Next, the tubes were stored in a Dewar of $\mathrm{LN}_{2}$ for $24 \mathrm{~h}$. After $\mathrm{LN}_{2}$ exposure, the $\mathrm{Al}$ tubes were rewarmed rapidly, transferred to a water bath thermostat (containing sterile distilled water) at $10 \pm 1{ }^{\circ} \mathrm{C}$ for $30 \mathrm{~s}$ (warming rate: $6.2{ }^{\circ} \mathrm{C} \mathrm{s}^{-1}$ ), washed in $0.1 \mathrm{M}$ sucrose, and stored at $0{ }^{\circ} \mathrm{C}$ for $20 \mathrm{~h}$.

In vitro survival testing of excised embryonic axes

EAs were excised with a $0.5 \mathrm{~mm}$ segment of the cotyledon and were then surface sterilized using a 3-step protocol: (1) 
$0.1 \%$ mercuric chloride for $10 \mathrm{~min}$; (2) $10 \%$ Domestos (sodium hypochlorite $\mathrm{NaClO}<5 \%$ ) for $10 \mathrm{~min}$; and (3) $75 \%$ ethyl alcohol for $1.0 \mathrm{~min}$. EAs subjected to each respective desiccation step alone, to desiccation and prefreezing at $-40{ }^{\circ} \mathrm{C}$, or to the two steps as well as freezing in $\mathrm{LN}_{2}$ were tested. EAs were then transferred onto recovery woody plant medium (WPM) (McCown and Lloyd 1981). The $\mathrm{pH}$ of the medium was adjusted to 5.5 before sterilization. Embryonic axes were cultured on WPM solid medium in Petri dishes ( $20 \mathrm{ml}$ medium) under standard conditions $\left(23 \pm 1{ }^{\circ} \mathrm{C}\right)$ for 6 days in the dark in a growth chamber (Mytron WB 750 KHFL Germany). For regrowth, the conditions of chamber were $23{ }^{\circ} \mathrm{C}$ with a $16 \mathrm{~h}$ photoperiod under a photon flux of $40 \mu \mathrm{mol} \mathrm{m} \mathrm{m}^{-2} \mathrm{~s}^{-1}$. After 3 weeks, the surviving explants were transferred onto the same medium in culture tubes $(150 \times 25 \mathrm{~mm})$. Viability and plant recovery were evaluated at 1 -week intervals for up to three months and were assessed as the percentage of the total number of embryonic axes. An embryonic axis was scored as viable when growth was observed in both the root and the shoot. A normal seedling was determined to be one that produced both a shoot and a first pair of leaves.

\section{Determination of cell membrane degradation}

Membrane degradation in embryonic axes was assessed on the basis of an electrolyte leakage (EL) test and a lipid peroxidation assay by determining the malondialdehyde (MDA) content. For the electrolyte leakage assay (Pukacki and Pukacka 1987), with the minor modification), embryonic axes (five replicates, $n=10$ ) were placed in tubes with double-distilled water $\left(0.1 \mathrm{~g} \mathrm{ml}^{-1}\right)$ for $24 \mathrm{~h}$ at room temperature. Subsequently, the conductivity of the solutions was measured using a temperature-compensating conductivity meter (CPC-551, Elmetron, Poland). For measuring total ion leakage from cells, the samples were subjected to a sudden freeze-thaw cycle $\left(20 /-60{ }^{\circ} \mathrm{C}\right.$ and to $20{ }^{\circ} \mathrm{C}$ ) at $50{ }^{\circ} \mathrm{C} / \mathrm{min}$ to induce total membrane breakdown. The leachate from the EAs was subjected to a second conductivity measurement after $24 \mathrm{~h}$ of soaking at room temperature. The membrane injury of the tissues was defined as the percentage of ions leaked relative to the total electrolyte content of the sample.

Lipid peroxidation was determined by measuring the formation of MDA, a product of lipid peroxidation, in a thiobarbituric reaction, according to Heath and Packer (1968).

Pre-weighed EAs (five axes in each sample) were homogenized and suspended in $5 \%$ trichloroacetic acid (TCA) and $2 \mathrm{ml}$ of $0.5 \%$ TBA in $20 \%$ TCA. The homogenate was then heated at $95{ }^{\circ} \mathrm{C}$ for $30 \mathrm{~min}$ and incubated on ice thereafter for $10 \mathrm{~min}$. The absorption of the thiobarbituric acid-malondialdehyde (TBA-MDA) complex was measured at $532 \mathrm{~nm}$ and corrected for nonspecific turbidity at $600 \mathrm{~nm}$. The concentration of MDA was calculated using a molar extinction coefficient of $155 \mathrm{nM}^{-1} \mathrm{~cm}^{-1}$. Each data point represents the mean \pm SD of five measurements (Pukacki and KaminskaRozek 2013b).

TTC (2,3,5-triphenyl tetrazolium chloride) reduction analyses

This test was performed on fresh EAs following each cryopreservation procedure using three replicates of $n=10$ each. EAs were transferred to tubes with $2 \mathrm{ml}$ of $0.6 \%$ TTC in $50 \mathrm{mM}$ potassium phosphate buffer $(\mathrm{pH} 7.5)$ containing $0.05 \%$ Tween. The samples were then vacuum infiltrated by a single cycle of $15 \mathrm{~min}$ at $0.8 \mathrm{~atm}$ with occasional mixing until the embryonic axes sank to the bottom. The tubes were then incubated at $25 \pm 1{ }^{\circ} \mathrm{C}$ for $24 \mathrm{~h}$ to allow the production of triphenyl formazan (TF). The EAs were homogenized and extracted in $95 \%$ ethanol. The homogenate was vortexed and centrifuged at $8,000 \mathrm{rpm}$ for $5 \mathrm{~min}$. The absorbance of the ethanol fraction was read at $520 \mathrm{~nm}$ in a UV-VIS $2401 \mathrm{PC}$ spectrophotometer (Shimadzu Scientific Instruments, Columbia, MD, USA). The concentration of triphenyl formazan was expressed as a percentage of the control using the formula:

$\mathrm{TF}=A_{\lambda=520}$ treated axes $/ A_{\lambda=520}$ for non-treated samples $\times 100$.

Statistical analysis

The data are presented as the mean $\pm \mathrm{SD}$. The data for all embryos throughout the treatment process were subjected to ANOVA analysis using Statgraphics Plus software. Data were analyzed by linear and nonlinear regression. Significant differences between the means were determined using Newman-Keuls range test, and significance was determined when $P<0.05$. For all regression analyses, the percentages were transformed (arcsin) such that the data conformed to parametric test assumptions.

\section{Results}

Stratification seeds

Figure 1 shows that after cold stratification of seeds of both Acer species, their embryonic axes after desiccation are more tolerant after exposure to liquid nitrogen than those no stratified seeds. The survival of $A$. platanoides after stratification was $13-42 \%$ higher comparing to not 


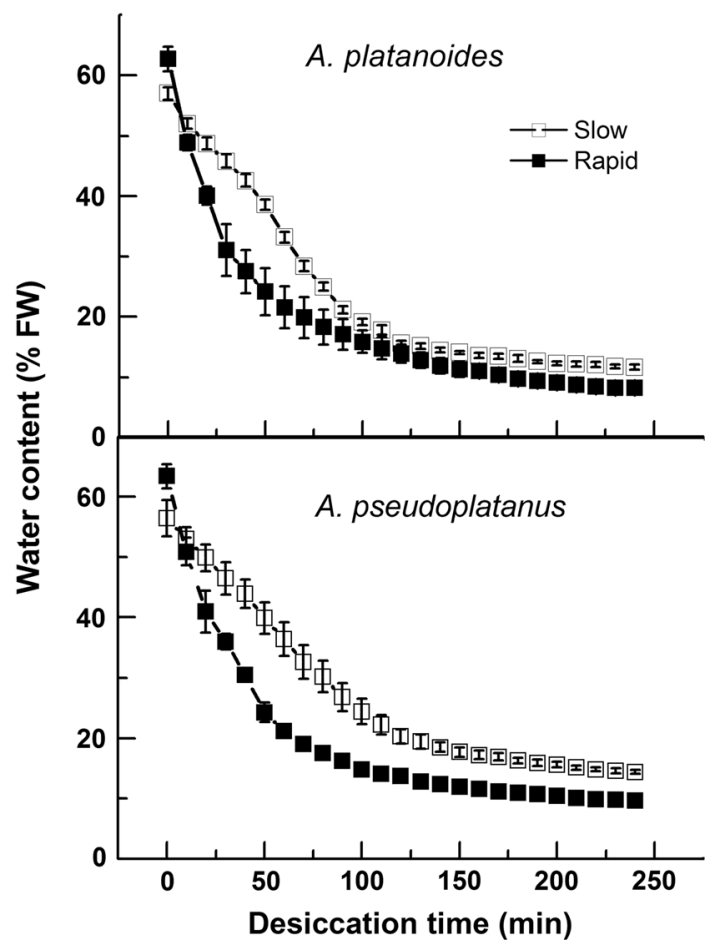

Fig. 2 The water content of embryonic axes of A. platanoides and A. pseudoplatanus subjected to rapid (solid squares) or slow (open squares) desiccation. Each point represents the mean water content of ten replicate axes

stratified ones in range of desiccation 10-30\% WC. In the case of A. pseudoplatanus the survival of stratified EAs was about $10 \%$ higher in range of desiccation 15-20\% WC comparing to ones that were not stratified.

Dehydration of embryonic axes

The effects of the dehydration method on water loss in EAs are presented in Fig. 2. For the first $60 \mathrm{~min}$ of slow dehydration at $6{ }^{\circ} \mathrm{C}$, the rate of water loss from embryonic axes of orthodox axes A. platanoides was $0.046 \mathrm{mg} \mathrm{H}_{2}$ $\mathrm{O} \mathrm{min}^{-1}$, while in a "flash" dryer, as described by WesleySmith et al. (2001a), the rate was increased to $0.079 \mathrm{mg} \mathrm{H}_{2} \mathrm{O} \mathrm{min}^{-1}$ (Fig. 2). For recalcitrant axes $A$. pseudoplatanus, the corresponding values were 0.046 and $0.094 \mathrm{mg} \mathrm{H}_{2} \mathrm{O} \mathrm{min}{ }^{-1}$, respectively (Fig. 2). This relationship is well described by quadratic regression. For $A$. platanoides, the coefficient of determination for slow dehydration was $r^{2}=98 \%$, while in the fast dehydration, this value was $r^{2}=91 \%$. For A. pseudoplatanus, the corresponding values were 99 and $92 \%(P<0.001)$, respectively. The $\mathrm{WC}$ of axes during fast dehydration was reduced from approximately $60 \%$ to approximately $20 \%$ during the first $60 \mathrm{~min}$ of drying and to approximately $10 \%$ after an additional 150 min (Fig. 2). a
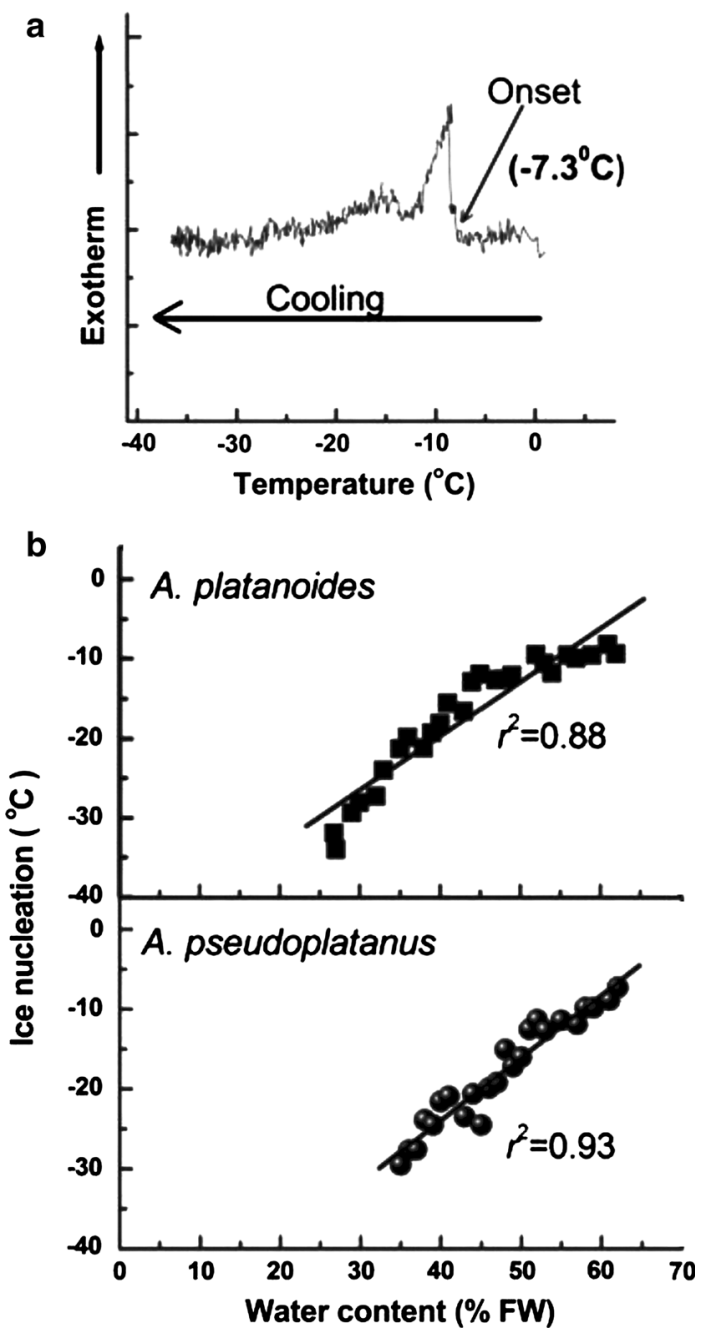

Fig. 3 Typical thermal transitions of cellular water during cooling indicating that the onset of ice nucleation occurred at $-7.3^{\circ} \mathrm{C}$ of $A$. platanoides embryonic axes with $61.0 \%$ water content (a) and ice nucleation temperature (b), for A. platanoides and A. pseudoplatanus embryonic axes as a function of different water content levels. $(P<0.001)$

Thermal analysis of tissue water

Desiccated embryonic axes of both Acer species were subjected to DTA to determine the ice nucleation temperature of water (Fig. 3). With decreasing WC in the tissues, decreased the temperature ice nucleation. The temperature of the freezing transition decreased from about $-8{ }^{\circ} \mathrm{C}$ (both species) to about $-29{ }^{\circ} \mathrm{C}$ for recalcitrant $A$. pseudoplatanus and to $-21{ }^{\circ} \mathrm{C}$ for orthodox A. platanoides after dehydration to $35 \% \mathrm{WC}$ embryonic axes (Fig. 3). The results of DTA showed that ice nucleation was not observed below a certain threshold level of WC. In orthodox A. platanoides, the WC threshold was $26.8 \%$, while for recalcitrant A. pseudoplatanus, it was $35.0 \%$. The ice nucleation temperatures of water at these 
Fig. 4 The relationship between water content and electrolyte leakage (a) and viability (b) of $A$. platanoides and $A$. pseudoplatanus embryonic axes during the steps of cryopreservation: dehydration, dehydration and pre-freezing to $-40{ }^{\circ} \mathrm{C}$, or a combination of both cycles (dehydration and pre-freezing and exposure to $\mathrm{LN}_{2}$ for $24 \mathrm{~h}$, assessments were performed for up to 3 months after treatment. The results are expressed as the means \pm SD of ten embryonic axes with three replicates

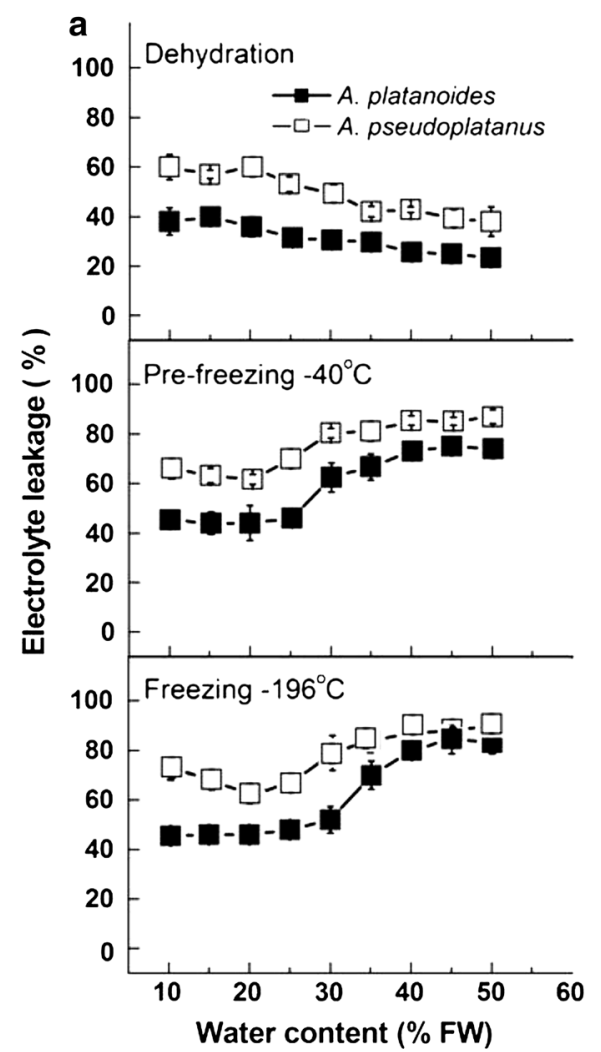

thresholds were -34.0 and $-29.5{ }^{\circ} \mathrm{C}$, respectively. A significant $(P<0.001)$ positive correlation was found between WC and exothermic onset of ice nucleation in EAs of both A. platanoides $\left(r^{2}=0.88\right)$, and A. pseudoplatanus $\left(r^{2}=0.93\right)$ (Fig. 3).

Membrane injury

Electrolyte leakage exceeded $50 \%$ after dehydration below $35 \%$ WC in A. pseudoplatanus, whereas after dehydration to $10 \% \mathrm{WC}$ in A. platanoides, the membrane permeability to electrolytes increased to $40 \%$ (Fig. 4a). Regression analysis showed a negative correlation between WC and electrolyte leakage from cells, the coefficient of determination for orthodox axes $A$. platanoides $\left(r^{2}=0.98, P<0.001\right)$ and recalcitrant axes $A$. pseudoplatanus $\left(r^{2}=0.97, P<0.001\right)$ (Table 1, 2). The electrolyte leakage from EAs of $A$. platanoides following dehydration to $40 \% \mathrm{WC}$ was twofold higher after freezing in $\mathrm{LN}_{2}$ that in non-cryostored axes (Fig. 4a). This result indicates that the membrane integrity of the EAs was changed significantly. Therefore, severe membrane injury appears to be correlated with the onset of viability loss, which was statistically significant at WCs of $30 \%$ and below (Fig. 4a). Linear regression revealed highly significant $(P<0.001)$ correlations between electrolyte leakage and post-cryo embryos survived of both $A$. platanoides $\left(r^{2}=0.93\right)$, and A. pseudoplatanus $\left(r^{2}=0.86\right)$, (Table 2$)$.

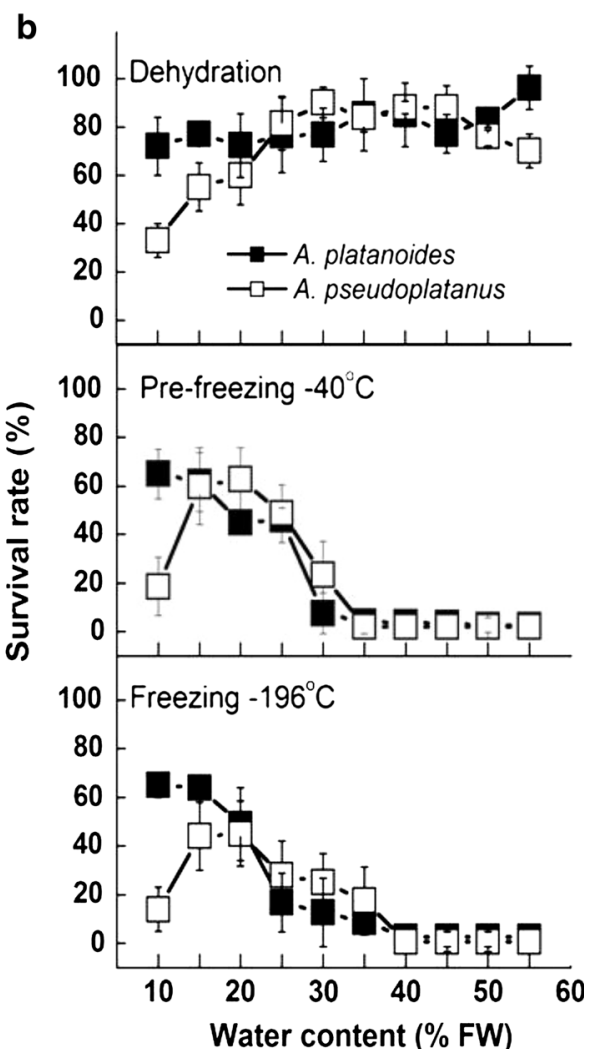

Malondialdehyde (MDA), as a product of lipid peroxidation, was also increased significantly in A. pseudoplatanus embryos after a combination of dehydration stress, cooling to $-40{ }^{\circ} \mathrm{C}$, and exposure to the temperature of $\mathrm{LN}_{2}$ (Fig. 5). In contrast, for A. platanoides, one-way ANOVA revealed no significant differences in MDA production between post-drying and post-cryo embryos, the variable WC showed a weak relationship with MDA (Fig. 5 and Tables 1, 2).

Survival

The rate of survival and development of EAs of orthodox of A. platanoides remained high when the $\mathrm{WC}$ was reduced to $25 \%$. Dehydration to $20 \%$ WC caused a $20 \%$ reduction in the survival rate (Fig. 4b). For A. platanoides, dehydration to a very low WC level of $3 \%$ (results not shown) led to a significant reduction in the survival rate of embryonic axes (to $30 \%$ ). Dehydration followed by cooling to $-40{ }^{\circ} \mathrm{C}$ resulted in a complete loss of viability in A. platanoides and in A. pseudoplatanus when the WC was reduced to $40-50$ and $35-50 \%$, respectively. This result was caused by intracellular ice in the embryonic axes. The highest survival rates for orthodox A. platanoides and recalcitrant $A$. pseudoplatanus embryonic axes were EAs of A. platanoides, when dried to 10-15\% WC, showed high survival rates (over $65 \%$ ) after cryostorage. 
Table 1 Coefficients of determination $\left(r^{2}\right)$ of linear regression between water content and; electrolyte leakage (EL), viability axes TTC reduction and MDA content, for three steps of cryopreservation: dehydration (D), dehydration and pre-freezing in $-40{ }^{\circ} \mathrm{C}$ (prf $-40{ }^{\circ} \mathrm{C}$ ), and after both cycles and exposure in $\mathrm{LN}_{2}$, of embryonic axes $A$. platanoides and $A$. pseudoplatanus

\begin{tabular}{|c|c|c|c|c|c|c|}
\hline \multirow[t]{2}{*}{ Parameter } & \multicolumn{3}{|c|}{ A. platanoides } & \multicolumn{3}{|c|}{ A. pseudoplatanus } \\
\hline & $\begin{array}{l}\text { Dehydration } \\
\text { (D) }\end{array}$ & $(\mathrm{D})+\left(\operatorname{prf}-40^{\circ} \mathrm{C}\right)$ & $\begin{array}{l}\text { (D) }+\left(\text { prf }-40{ }^{\circ} \mathrm{C}\right) \\
+\mathrm{LN}_{2}\end{array}$ & $\begin{array}{l}\text { Dehydration } \\
\text { (D) }\end{array}$ & (D) $+($ prf-40) & $\begin{array}{l}\text { (D) }+(\text { prf-40) } \\
+\mathrm{LN}_{2}\end{array}$ \\
\hline EL & $0.98 * *$ & $0.86^{* *}$ & $0.77 * *$ & $0.97 * *$ & $0.86 * *$ & $0.73^{*}$ \\
\hline Viability & $0.50 *$ & $0.85^{* *}$ & $0.84 * *$ & $0.82 * *$ & $0.52 *$ & $0.54 *$ \\
\hline TTC & $0.64 *$ & $0.80 * *$ & $0.94 * *$ & $0.80 * *$ & $0.88 * *$ & $0.95^{* *}$ \\
\hline MDA & 0.39 (ns) & 0.04 (ns) & 0.04 (ns) & 0.70 * & 0.05 (ns) & $0.72 *$ \\
\hline
\end{tabular}

$n s$ not significant

$* P<0.05$

** $P<0.001$

Table 2 The linear regression $\left(r^{2}\right)$ between viability embryonic axes and electrolyte leakage (EL), TTC reduction and MDA content, for three steps of cryopreservation: dehydration (D), dehydration and pre- freezing to $-40{ }^{\circ} \mathrm{C}$ (prf $-40{ }^{\circ} \mathrm{C}$ ), and after both cycles and exposure in $\mathrm{LN}_{2}$, of embryonic axes A. platanoides and A. pseudoplatanus

\begin{tabular}{|c|c|c|c|c|c|c|}
\hline \multirow[t]{2}{*}{ Parameter } & \multicolumn{3}{|c|}{ A. platanoides } & \multicolumn{3}{|c|}{ A. pseudoplatanus } \\
\hline & $\begin{array}{l}\text { Dehydration } \\
\text { (D) }\end{array}$ & $(\mathrm{D})+\left(\operatorname{prf}-40^{\circ} \mathrm{C}\right)$ & $\begin{array}{l}\text { (D) }+\left(\operatorname{prf}-40^{\circ} \mathrm{C}\right) \\
+\mathrm{LN}_{2}\end{array}$ & $\begin{array}{l}\text { Dehydration } \\
\text { (D) }\end{array}$ & (D) $+(\operatorname{prf}-40)$ & $\begin{array}{l}\text { (D) }+(\text { prf-40) } \\
+\mathrm{LN}_{2}\end{array}$ \\
\hline EL & $0.48 *$ & $0.79 * *$ & $0.93 * *$ & $0.75 * *$ & $0.78 * *$ & $0.86^{* *}$ \\
\hline TTC & $0.47 *$ & $0.91 * *$ & $0.84 * *$ & $0.57 *$ & $0.67 * *$ & $0.81 * *$ \\
\hline MDA & $0.62 *$ & $0.04(\mathrm{~ns})$ & $0.01(\mathrm{~ns})$ & $0.42 *$ & $0.08(\mathrm{~ns})$ & $0.48 *$ \\
\hline
\end{tabular}

$n s$ not significant

$* P<0.05$

** $P<0.001$

However, in A. pseudoplatanus, the highest survival rate was recorded after a combination of drying, cooling to $40{ }^{\circ} \mathrm{C}$, and $\mathrm{LN}_{2}$ treatment $(70 \%)$ when the axes were dried to $15-20 \%$ WC (Fig. 4b). Linear regression revealed highly significant $(P<0.001)$ correlations between $\mathrm{WC}$ and the survival rate of embryonic axes after cooling to $40{ }^{\circ} \mathrm{C}$ and after cryostorage in A. platanoides (Tables 1, 2). When the WC of embryonic axes of both species was $40-50 \%$, none of the post-cryo embryos survived (Fig. 4b).

\section{TTC reduction test}

The percentage reduction of TTC in EAs of both Acer species (Fig. 5) after the combination of drying and cooling to $-40{ }^{\circ} \mathrm{C}$, or after both pretreatments followed by cryostorage, was significantly correlated with water content (Tables 1, 2; Fig. 6). The freezing stress to -40 and $-196{ }^{\circ} \mathrm{C}$ induced a significant decrease in TTC reduction at higher WC (40-50 \%) for the embryonic axes of both species. However, cryostored embryonic axes of A. pseudoplatanus showed the highest TTC reduction (approximately $67 \%$ ) at 15-25\% WC., while for cryostored A. platanoides, the TTC reduction was higher than $85 \%$ at 10-20\% WC, indicating its viability after exposure to $\mathrm{LN}_{2}$ (Fig. 6). Linear regression for $10-50 \% \mathrm{WC}$ revealed highly significant $(P<0.001)$ correlations, coefficient of determination between injury of cell membranes (i.e., electrolyte leakage after cryostorage of embryonic axes) and TTC reduction for both $A$. platanoides $\left(r^{2}=0.94\right)$ and $A$. pseudoplatanus $\left(r^{2}=0.92\right)$ (Fig. 6). Linear regression revealed highly significant $(P<0.001)$ correlations, coefficient of determination, between TTC reduction and the survival rate of embryonic axes after the combination of drying and cooling to $-40{ }^{\circ} \mathrm{C} \quad\left(r^{2}=0.91\right)$ and after cryostorage axes $\left(r^{2}=0.84\right)$ for A. platanoides and A. pseudoplatanus $r^{2}=0.67$ and $r^{2}=0.81$, respectively (Table 2 ).

\section{Discussion}

Response to dehydration stress

A. platanoides and A. pseudoplatanus are important species in Europe; however, these species have not been utilized in cryopreservation studies until now. The present study 


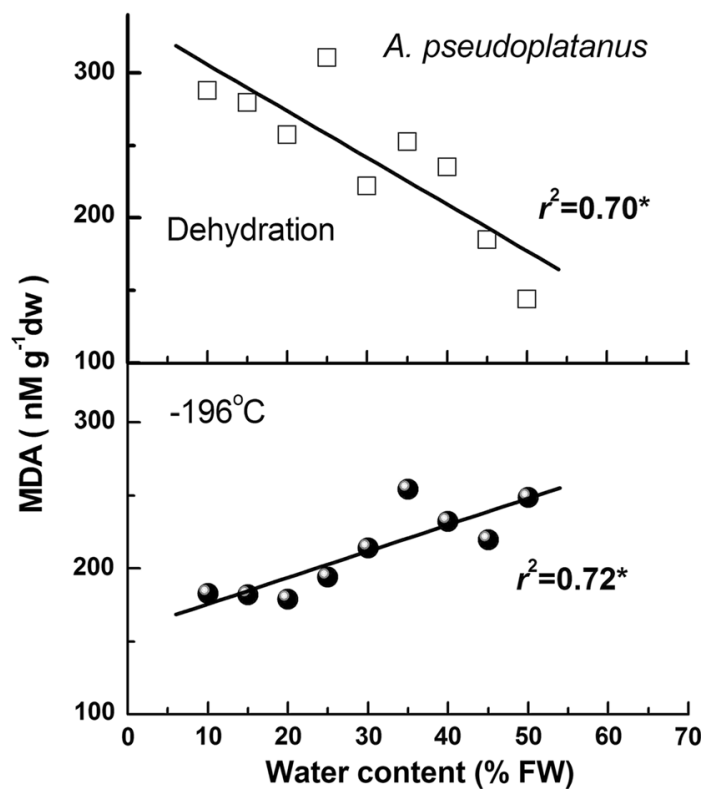

Fig. 5 The relationship between water content and lipid peroxidation (represented as the level of MDA content) of A. pseudoplatanus embryonic axes that were subjected to dehydration, pre-freezing to $-40{ }^{\circ} \mathrm{C}$ and exposed to $\mathrm{LN}_{2}$

demonstrates that EAs of these seeds can be successfully subjected to freezing in $\mathrm{LN}_{2}$ after fast desiccation in the air and cooling to $-40{ }^{\circ} \mathrm{C}$. Initial experiments revealed that seed stratification is necessary before commencing the dehydration and cryo-freezing protocol (Fig. 1). Maple seeds contain inhibitors of germination which may be present in the seed embryo/or cover. A. platanoides seeds characterized deep dormancy, while the A. pseudoplatanus seeds have forced dormancy. The dormancy of the seeds can be break through subjecting to the cold stratification at $3{ }^{\circ} \mathrm{C}$ (Suszka et al. 1996).

The second most important stage of our experiments was the exothermic analysis (i.e., DTA) of embryonic axes, which allowed us to determine safe WCs in tissues for the second step of cryopreservation, i.e., cooling to $-40{ }^{\circ} \mathrm{C}$. Another improvement was the combination of partial rapid drying and cooling, which led to increased survival and reduced cellular damage of the axes as reported previously (Wesley-Smith et al. 2001b). The rapid drying increases the extent of water loss tolerated by recalcitrant material by reducing the time of exposure to potentially harmful intermediate water contents (Walters et al. 2001).

The first symptoms of freezing damage in plant tissues (caused by stress factors) can be observed in cytoplasmic membranes (Steponkus 1984). Thus, the tolerance of embryonic axes to seed desiccation can be assessed by measuring cell membrane permeability to ions during dehydration of embryonic axes. Membrane permeability to ions increases in desiccated embryonic axes of several species that produce seeds that are classified as recalcitrant (Song et al. 2004; Ntuli et al. 2011). In isolated embryonic axes of Acer species, the level of desiccation was also positively correlated with an increase in electrolyte leakage (Fig. 4), which is a classic measurement of membrane integrity. In the embryonic axes of $A$. pseudoplatanus, the increase in membrane permeability
Fig. 6 The effect of water content on dehydration, prefreezing to $-40{ }^{\circ} \mathrm{C}$ or both cycles and exposure to $\mathrm{LN}_{2}$ on triphenyl tetrazolium chloride (TTC) reduction (a) of $A$. platanoides and $A$. pseudoplatanus embryonic axes and (b) relationship between TTC reduction and electrolyte leakage for both Acer sp., embryonic axes following exposed to $\mathrm{LN}_{2}\left(r^{2}\right.$ at $P<0.001)$

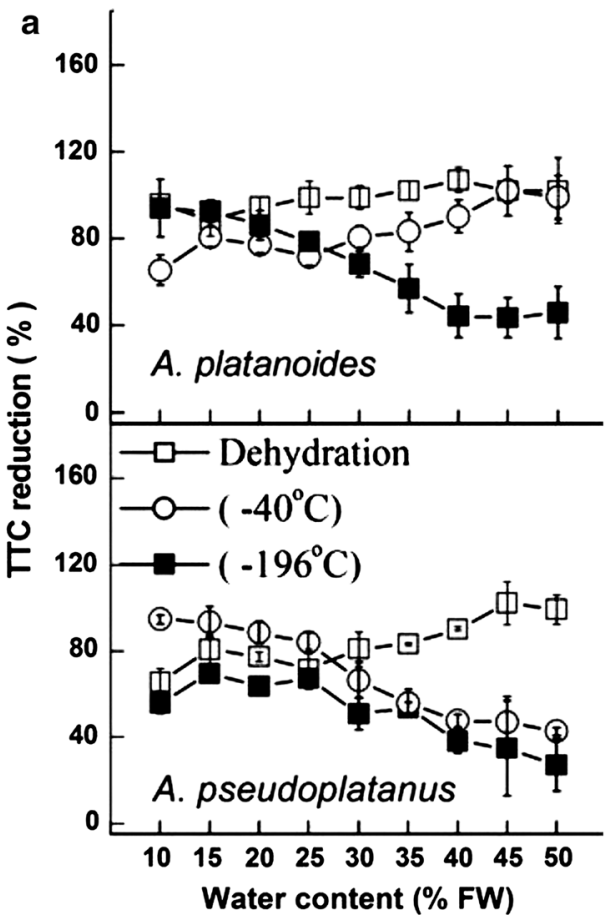


above the lethal level after desiccation to less than $20 \%$ WC suggests that embryonic axes of seeds of this species are sensitive to desiccation stress (Fig. 4a). Membranes are commonly regarded as the primary site of desiccation injury in seeds (Senaratna and McKersie 1986; Engelmann 2011).

The orthodox seeds of $A$. platanoides tolerated dehydration to 8-10 \% WC (Hong and Ellis 1990), while in embryonic axes of A. pseudoplatanus, if the WC declined to $8 \%$, the survival rate was $50 \%$ lower than that in the control, a similar situation (Fig. 4b). It can be considered that this is due to vitrification of embryonic axes. Vitrification is now known to play a central role in cryopreservation of biological materials, even in cryopreservation by slow freezing. To a certain extent phenomenon can be compared to the study by Mazur (Mazur 1984). The cells can survive the freezing process, if ice crystals are relatively small (Wesley-Smith et al. 2014). As cooling and ice growth continue, eventually the solute concentration in and around cells becomes so high that water in the solution cannot freeze. In woody plant seeds, the presence of the vitrification state at room temperatures was determined in EAs of Fagus sylvatica (Pukacka et al. 2003).

Usually the axes behave as seeds. Often, they are more tolerant than seeds. However, of such comparison researches are a few. For Avicennia marina had greater tolerance to the dehydration embryonic axes in comparison to whole seed (Farrant et al. 1993). Embryonic axes of the recalcitrant seeds were much more tolerant to desiccation than whole seeds, (Dickie et al. 1991; FinchSavage 1992; Pukacka and Ratajczak 2007). Viable embryonic axes were observed even after drying to $10 \%$ (Fig. 4b). Seeds of a species from the intermediate category ( $F$. sylvatica, which is very similar to A. platanoides) tolerate water loss to a WC of approximately $10 \%$. In embryonic axes of $F$. sylvatica, the survival rate declined to 8-10 \% after desiccation (Pukacki et al. 2011; Rachocki et al. 2014).

\section{Response to cryostorage}

Vital stains by triphenyl tetrazolium chloride (TTC) are frequently used to determine viability of plant tissues (Lin et al. 2001). The highly significant $(P<0.001)$ correlation between electrolyte leakage and TTC reduction after exposure to $\mathrm{LN}_{2}\left(r^{2}=0.95\right)$ confirms that TTC reduction measurements can be used for viability assessment.

As a result of the stages of cryopreservation (combination of desiccation, cooling to $-40{ }^{\circ} \mathrm{C}$, and exposure to $\mathrm{LN}_{2}$ ), further damage may take place in membranes, leading to a loss of their semi-permeability and finally to cell death (Fig. 4b). An increase in membrane permeability was observed in the studied species if tissues with high WCs were frozen; this was a result of ice crystallization (Fig. 3). A decrease in the WC of embryonic axes was associated with an increase in osmotic pressure. This increase resulted in a decrease in freezing temperature and in cytoplasm vitrification, which prevented ice nucleation in the cells (Wolfe and Bryant 2001). The optimum WC range of Acer embryonic axes, without causing further tissue damage during freezing, was $10-25 \%$ for A. platanoides and 15-25\% for A. pseudoplatanus. At such levels of WC, the cell membrane permeability for the individual species after freezing was nearly the same as that observed immediately after desiccation. Similar results after freezing were obtained for embryonic axes of Aesculus hippocastanum, another species with recalcitrant seeds (WesleySmith et al. 2001b). Therefore, it is clear that responses of different species to cryostorage after desiccation may vary, and this could be attributed to genotypic differences between species.

The high permeability of plant cell membranes to ions is associated with accumulation of the products of membrane fatty acid peroxidation (Leprince et al. 1995). In this study, we measured the level of thiobarbituric acid (TBA)-reactive products of peroxidation, mostly malondialdehyde (MDA) (Fig. 5). Because of the low concentration of polyunsaturated linolenic acid in the membranes of embryonic axes of A. platanoides, assessment of the concentration of TBA-reactive products of peroxidation is not a reliable method for lipid peroxidation assessment (Pukacka 1999). In contrast, in A. pseudoplatanus, TBAreactive products of peroxidation were accumulated as a result of desiccation. MDA content in A. pseudoplatanus was correlated with increasing dehydration stress and reached the highest values after desiccation to less than $25 \%$ WC. After cooling to $-40{ }^{\circ} \mathrm{C}$ and exposure to $\mathrm{LN}_{2}$, the MDA content was higher at higher WC levels. However, the MDA content decreased in the WC range of 10-25\%, which was also associated with a decrease in the permeability of the membrane to ions and viability of embryonic axes (Table 2).

Desiccation and freezing of plant tissues is linked with ROS production. ROS cause oxidative damage, including peroxidation of fatty acids in cell membranes. Accumulation of ROS (e.g., the superoxide radical $\left(\mathrm{O}_{2}^{--}\right)$and hydrogen peroxide $\left(\mathrm{H}_{2} \mathrm{O}_{2}\right)$ under the influence of dehydration has been reported in embryonic axes of seeds classified as intermediate (e.g., Azadirachta indica (Varghese and Naithani 2008) and the recalcitrant Acer saccharinum (Beardmore and Whittle 2005; Pukacka and Ratajczak 2006). Cryostorage of embryonic axes of $A$. platanoides and A. pseudoplatanus at $-196{ }^{\circ} \mathrm{C}$ proved to be possible after a two-step procedure involving desiccation and cooling to $-40{ }^{\circ} \mathrm{C}$. Dehydration allowed for 
removal of the water that could otherwise be transformed into ice, leading to cell membrane damage and death. Dehydration is the most common method used for cryopreservation of embryonic axes isolated from seeds; it allows axes of Camellia sinensis (Kuranuki and Yoshida 1996); Aesculus, Castanea, and Quercus species (Pence 1990); Poncirus trifoliata (Radhamani and Chandel 1992); and Azadirachta indica (Varghese and Naithani 2008) to be safely frozen in $\mathrm{LN}_{2}$. For A. platanoides, a species that produces desiccation-tolerant seeds, the optimum WC for cooling to $-40{ }^{\circ} \mathrm{C}$ and exposure to $\mathrm{LN}_{2}$ was $10-15 \%$. For the recalcitrant seeds of A. pseudoplatanus, the best cryopreservation results were achieved with a slightly higher WC (15-20\%). A comparison of the results indicates that the desiccation tolerance of embryonic axes was significantly decreased in $A$. pseudoplatanus when the WC was below $15 \%$, while tolerance to cryopreservation began to decline at $25 \%$ WC in both species.

In summary, successful cryopreservation using aerial desiccation and cooling to $-40{ }^{\circ} \mathrm{C}$ was achieved for embryonic axes of both Acer species. Free water crystallization in cells is not observed if the WC is lower than $26.8 \%$ in orthodox axes A. platanoides and lower than $35.0 \%$ in recalcitrant axes A. pseudoplatanus. The safe range of seed WC for survival and development of embryonic axes subjected to initial cooling to $-40{ }^{\circ} \mathrm{C}$ and subsequent exposure to $\mathrm{LN}_{2}$ is $10-15 \%$ for the orthodox A. platanoides and $15-20 \%$ for the recalcitrant $A$. pseudoplatanus. In the embryonic axes of $A$. pseudoplatanus, desiccation to a WC below $15 \%$ led to a dramatic reduction of viability. However, in A. platanoides, after drying to $10 \% \mathrm{WC}$, the high survival of post-cryo embryonic axes did not indicate any critical damage to cells. The data suggest that tissue water status is more important for cryopreservation of embryonic axes in recalcitrant $A$. pseudoplatanus than in orthodox $A$. platanoides.

Author contribution statement P.M. P. planned the experiments, and supervised biophysical and biochemical analyses, contributed to data interpretation and prepared the manuscript. K. J., performed biochemical determinations, and partly data interpretation.

Acknowledgments We thank Mariola Matelska for technical assistance. This research was supported by the Polish Ministry of Science and Higher Education and National Science Centre (NCN), grant no. N N309 101836 (to PMP).

Conflict of interest The authors declare that they have no conflict of interest.

Open Access This article is distributed under the terms of the Creative Commons Attribution License which permits any use, distribution, and reproduction in any medium, provided the original author(s) and the source are credited.

\section{References}

Beardmore T, Whittle CA (2005) Induction of tolerance to desiccation and cryopreservation in silver maple (Acer saccharinum) embryonic axes. Tree Physiol 25:965-972

Benson EE (2008a) Cryopreservation theory. In: Reed BM (ed) Plant cryopreservation: a practical guide. Springer, New York, pp 15-32

Benson EE (2008b) Cryopreservation of phytodiversity: a critical appraisal of theory and practice. Crit Rev Plant Sci 27:141-219

Benson EE, Johnston J, Muthusamy J, Harding K (2006) Physiological and engineering perspectives of in vitro plant cryopreservation. In: Gupta D, Ibaraki Y (eds) Plant tissue culture engineering. Springer, Netherlands, pp 441-476

Berjak P, Pammenter NW (2008) From Avicennia to Zizania: seed recalcitrance in perspective. Ann Bot 101:213-228

Berjak P, Walker M, Watt MP, Mycock DJ (1999) Experimental parameters underlying failure or success in plant germplasm cryopreservation: a case study on zygotic axes of Quercus robur L. Cryoletters 20:252-262

Berjak P, Mycock DJ, Walker M, Kioko JI, Pammenter NW, WesleySmith J (2000) Conservation of genetic resources naturally occurring as recalcitrant seeds. In: Black M, Bradford KJ, Vásquez-Ramos $\mathbf{J}$ (eds) Seed biology: Advances and applications. CABI, Wallingford, pp 223-228

Berjak P, Bartels P, Benson EE, Harding K, Mycock DJ, Pammenter NW, Sershen, Wesley-Smith J (2010) Cryoconservation of South African plant genetic diversity. In Vitro Cell Dev Biol-Plant 47(1):65-81

Dickie JB, Pritchard HW (2002) Systematic and evolutionary aspects of desiccation tolerance in seeds. In: Black M, Pritchard HW (eds) Desiccation and survival in plants. CABI Publishing, Drying without dying, pp 239-259

Dickie JB, May K, Morris SVA, Titley SE (1991) The effects of desiccation on seed survival in Acer platanoides L. and Acer pseudoplatanus L. Seed Sci Res 1:149-162

Engelmann F (2004) Plant cryopreservation: progress and prospects. In Vitro Cell Dev Biol-Plant 40:427-433

Engelmann F (2011) Cryopreservation of embryos: an overview. In: Thorpe AT, Yeung EC (eds) Plant embryo culture: methods and protocols, methods in molecular biology, vol 710. Springer SciBusiness Media, New York, pp 155-183

Farrant JM, Berjak P, Pammenter NW (1993) Studies on the development of the desiccation sensitive (recalcitrant) seeds of Avicennia marina. The acquisition of germinability and responses to storage and dehydration. Ann Bot 71:405-410

Fernandes P, Rodriguez E, Pinto G, Roldan-Ruiz I, De Loose M, Santos C (2008) Cryopreservation of Quercus suber somatic embryos by encapsulation-dehydration and evaluation of genetic stability. Tree Physiol 28:1841-1850

Finch-Savage WE (1992) Embryo water status and survival in the recalcitrant species Quercus robur L.: evidence for a critical moisture content. J Exp Bot 43:663-669

Hong TD, Ellis RH (1990) A comparison of maturation drying, germination and desiccation tolerance between developing seeds of Acer pseudoplatanus L. and Acer platanoides L. New Phytol 116:589-596

Kaczmarczyk A, Funnekotter B, Menon A. Phang PY, Hanbali AA, Bunn E. Ricardo L. Mancera ERL (2012) Current issues in plant cryopreservation. In: Katkov II (ed) Current frontiers in cryobiology agricultural and biological sciences. InTech, Croatia, pp 417-438

Kuranuki Y, Yoshida S (1996) Different responses of embryonic axes and cotyledons from tea seeds to desiccation and cryoexposure. Breed Sci 46:149-154 
Leprince O, Vertucci CW, Hendry G, Atherton NM (1995) The expression of desiccation-induced damage in orthodox seeds is a function of oxygen and temperature. Physiol Plant 94:233-240

Lin HC, Chen BS, Yu CW, Chiang SW (2001) A water-based triphenyltetrazolium chloride method for the evaluation of green plant tissue viability. Phytochem Anal 12:211-213

Mazur P (1984) Freezing of living cells: mechanisms and implications. Am J Physiol 247:125-142

McCown B, Lloyd G (1981) Woody Plant Medium (WPM)-a mineral nutrient formation for microculture of woody plant species. Hort Sci 16:453

Niino T, Sakai A (1992) Cryopreservation of alginate-coated in vitrogrown shoot tips of apple, pear and mulberry. Plant Sci 87:199-206

Ntuli TM, Finch-Savage WE, Berjak P, Pammenter NW (2011) Increased drying rate lowers the critical water content for survival in embryonic axes of English oak (Quercus robur L.) seeds. J Integr Plant Biol 53:270-280

Pammenter NW, Berjak P (1999) A review of recalcitrant seed physiology in relation to desiccation-tolerance mechanisms. Seed Sci Res 9:3-37

Panis B, Lambardi M (2005) Status of cryocryopreservation technologies in plants (crops and forest trees). In: F. A.O. (ed) The role of biotechnology for the characterization and conservation of Crop Forest Animal and Fishery Genetic Resources in Developing Countries, Turin pp 43-54

Pence VC (1990) Cryostorage of embryo axes of several large-seeded temperate tree species. Cryobiology 27:212-218

Pritchard HW, Prendergast FG (1986) Effects of desiccation and cryopreservation on the in vitro viability of the recalcitrant seed species Araucaria hunstenii K Schum. J Exp Bot 37:1388-1397

Pukacka S (1983) Phospholipid changes and loss of viability in Norway maple (Acer platanoides L.) seeds. Zeits Pflanzenphysiol 112:199-205

Pukacka S (1999) Membrane phospholipid composition during maturation of seeds of Acer platanoides and Acer pseudoplatanus in relation to desiccation tolerance. Acta Physiol Plant 21:109-115

Pukacka S, Ratajczak E (2006) Antioxidative response of ascorbateglutathione pathway enzymes and metabolites to desiccation of recalcitrant Acer saccharinum seeds. J Plant Physiol 163:1259-1266

Pukacka S, Ratajczak E (2007) Ascorbate and glutathione metabolism during development and desiccation of orthodox and recalcitrant seeds of the genus Acer. Funct Plant Biol 34:601-613

Pukacka S, Hoffmann SK, Goslar J, Pukacki PM, Wojkiewicz E (2003) Water and lipid relations in beech (Fagus sylvatica L.) seeds and its effect on storage behaviour. Biochim Biophys Acta 1621(1):48-56

Pukacka S, Malec M, Ratajczak E (2011) ROS production and antioxidative system activity in embryonic axes of Quercus robur seeds under different desiccation rate conditions. Acta Physiol Plant 33:2219-2227

Pukacki PM, Kaminska-Rożek E (2013a) Reactive species, antioxidants and cold tolerance during deacclimation of Picea abies populations. Acta Physiol Plant 35:129-138

Pukacki PM, Kaminska-Rożek E (2013b) Differential effects of spring reacclimation and deacclimation on cell membranes of Norway spruce seedlings. Acta Soc Bot Pol 82:77-84

Pukacki PM, McKersie BD (1990) Supercooling and ice nucleation events in the crown of winter wheat seedlings. Can J Plant Sci 70:1179-1182

Pukacki PM, Pukacka S (1987) Freezing stress and membrane injury of Norway spruce (Picea abies) tissues. Physiol Plant 69:156-160
Pukacki PM, Kendall EJ, McKersie BD (1991) Membrane injury during freezing stress to winter wheat (Triticum aestivum L.) crowns. J Plant Physiol 138:516-521

Pukacki PM, Zenkteler E, Guźniczak E (2011) Cryopreservation of embryonic axes of Fagus sylvatica in relation to dehydration and thermal properties of tissue water. In: Cryopreservation Symposium COST Action 871, Final meeting, Agrocampus Ouest INHP, Angers, France, 8-11 February 2011, pp 12-12

Rachocki A, J, Kowalczuk, S, Pukacka, E, Zenkteler, Pukacki PM (2014) Influence of water content and temperature on ice nucleation and intracellular glasses in embryonic axes of suborthodox and recalcitrant seeds. In: Pukacki PM., Pukacka $\mathrm{S}$ (eds) The Book of Abstracts. 10 ${ }^{\text {th }}$ International Plant Cold Hardiness Seminar-Stress Recognition Triggers Plant Adaptation. Poznan, 17-21 Aug. pp 80. http://www.ipchs2014poznan. org/wp-content/uploads/2014/08/Book-of-Abstract1.pdf

Radhamani J, Chandel KPS (1992) Cryopreservation of embryonic axes of trifoliate orange Poncirus trifoliata [L.] RAE). Plant Cell Rep 11:372-374

Reed BM (2008) Cryopreservation-Practical consideration. In: Reed BM (ed) Plant cryopreservation: a practical guide. Springer, New York, pp 3-13

Santos IRI, Stushnoff C (2002) Cryopreservation of embryonic axes of Citrus species by encapsulation-dehydration. Plant Gen Res Newsletter 131:36-41

Senaratna T, McKersie BD (1986) Loss of desiccation tolerance during seed germination: a free radical mechanism of injury. In: Leopold AC (ed) Membranes, metabolism and dry organisms. Cornell University Press, Ithaca, pp 85-101

Sershen Berjak P, Pammenter NW, Wesley-Smith J (2012) Rate of dehydration, state of subcellular organization and nature of cryoprotection are critical factors contributing to the variable success of cryopreservation: studies on recalcitrant zygotic embryos of Haemanthus montanus. Protoplasma 249:171-186

Song SQ, Berjak P, Pammenter N (2004) Desiccation sensitivity of Trichilia dregeana axes and antioxidant role of ascorbic acid. Acta Bot Sinica 46:803-810

Steponkus PL (1984) Role of the plasma membrane in freezing injury and clod acclimation. Ann Rev Plant Physiol 35:543-584

Suszka B, Muller C, Bonnet-Masimbert M (1996) Seeds of forest broadleaves from harvest to sowing. INRA, Paris, pp 99-123

Varghese B, Naithani SB (2008) Oxidative metabolism-related changes in cryogenically stored neem (Azadirachta indica A. Juss) seeds. J Plant Physiol 165:755-765

Volk GM, Walters C (2006) Plant vitrification solution 2 lowers water content and alters freezing behavior in shoot tips during cryoprotection. Cryobiology 52:48-61

Walters C, Pammenter NW, Berjak P, Crane J (2001) Desiccation damage: 'Accelerated aging' and metabolism in desiccation tolerant and sensitive seeds. Seed Sci Res 11:135-148

Walters C, Wheeler L, Stanwood PC (2004) Longevity of cryogenically stored seeds. Cryobiology 48:229-244

Wesley-Smith J, Vertucci CW, Berjak P, Pammenter NW, Crane J (1992) Cryopreservation of desiccation sensitive axes of Camellia sinensis in relation to dehydration, freezing rate and the thermal properties of tissue water. J Plant Physiol 140:596-604

Wesley-Smith J, Pammenter NW, Berjak P, Walters C (2001a) The effects of two drying rates on the desiccation tolerance of embryonic axes of recalcitrant jackfruit (Artocarpus heterophyllus Lamk.) seeds. Ann Bot 88:653-664

Wesley-Smith J, Walters C, Pammenter NW, Berjak P (2001b) Interactions among water content, rapid (nonequilibrium) cooling to $-196^{\circ} \mathrm{C}$, and survival of embryonic axes of Aesculus hippocastanum L. seeds. Cryobiology 42:196-206 
Wesley-Smith J, Pammenter NW, Walters C, Berjak P (2014) Intracellular ice and cell survival in cryo-exposed embryonic axes of recalcitrant seeds of Acer saccharinum: an ultrastructural study of factors affecting cell and ice structures. Ann Bot 13:695-709 